\title{
The electron heating rate and ion chemistry in the thermosphere above Wallops Island during the solar eclipse of ry March 1970
}

\author{
L. H. Brace, H. G. Mayr, M. W. Pharo III, L. R. Scott \\ and N. W. SPEncer \\ Goddard Space Flight Center, Greenbelt, Maryland, U.S.A.
}

and

G. R. Carignan

Departmont of Electrical Engineering, University of Michigan, Ann Arbor, Michigan, U.S.A.

(Received 24 November 1971)

\begin{abstract}
An identical pair of thermosphere probes measured the $\mathrm{N}_{2}$ concentration and temperature, the ion composition and concentrations and the electron temperature up to $290 \mathrm{~km}$ about $30 \mathrm{~min}$ and $5 \mathrm{~min}$ before totality during the 7 March 1970 eclipse at Wallops Island. The rockets travelled similar trajectories thus permitting the purely temporal changes between flights to be resolved. The neutral temperature and $\mathrm{N}_{2}$ concentration changed little but the electron temperature decreased by as much as 20 per cent in the lower $F$-region. The ion concentration decreased by about 30 per cent in the $F$-region and about 50 per cent in the $E$-region, with little change in relative ion composition. The electron cooling rates decreased by a factor of 6 in the lower $F$-region, approximately in proportion to the change in visible solar disc. A smaller than expected decrease in the cooling rate below $150 \mathrm{~km}$ between the two flights indicates a hardening of the solar spectrum and suggests a significant heat contribution from the solar corona near totality. The ion composition measurements were consistent with solutions of the ion continuity equations. A proper fit required a factor of three enhancement of the flux below $200 \AA$, an amount also consistent with the electron heat balance analysis. Reactions involving the minor ions $\mathrm{N}^{+}$and $\mathrm{N}_{2}{ }^{+}$were found to be important for the ion chemistry of the major ions $\mathrm{O}_{2}{ }^{+}$and $\mathrm{NO}^{+}$, especially at the time of eclipse. The negligible response of the neutral atmosphere to the eclipse is reasonable considering the long time constants for the conductive and convective transport processes and the local nature of the disturbance.
\end{abstract}

\section{INTRODUCTION}

THE OccuRREnce of a solar eclipse at Wallops Island on 7 March 1970 presented a unique opportunity to investigate the response of the thermosphere and ionosphere to rapidly changing solar illumination at a low zenith angle. The response times of this region depend inherently upon the ion reaction rates, the electron, ion and neutral cooling rates, and perhaps on dynamic effects associated with the rapid changes occurring during the eclipse. To investigate these changes, two identical Thermosphere Probes, NASA 18.104 and 18.105, were launched southeastward from Wallops Island into the path of the approaching cone of totality. At the apogee altitude of $290 \mathrm{~km}$, the percentage obscuration had reached 42 and 84 per cent, respectively. The two rockets were launched along essentially identical paths to permit the purely temporal, eclipse-induced changes to be separated from any spatial variations that might otherwise have been encountered.

In this paper, the resulting measurements of ion composition, total ion concentration, $N_{i}$, molecular nitrogen concentration $n\left(\mathrm{~N}_{2}\right)$ and temperature, $T_{\mathrm{N}_{2}}$, and electron 
temperature, $T_{e}$, are presented and these data are analyzed in terms of the electron heat balance and ion photochemistry.

\section{The Instruments}

The Thermosphere Probe (TP) is an ejectable, vacuum-tight package that can carry several instruments to altitudes of about $290 \mathrm{~km}$ when launched by a NikeTomahawk vehicle. The TP has been described by SPEncer et al. $(1965,1969)$. Briefly, the Thermosphere Probe is a long cylindrical package that is ejected from a clam-shell nose cone at about $70 \mathrm{~km}$, ascends to apogee and returns to the Earth. After ejection, the TP tumbles end over end in a nearly vertical plane with a period of typically 3-4 sec, thus exposing its instrument sensors to essentially all angles of attack during each tumble.

The instruments employed in each of these two flights were an omegatron mass spectrometer, a Bennett ion mass spectrometer, and a cylindrical electrostatic probe. These instruments have been described elsewhere (Spencer et al., 1965, 1969; Pharo et al., 1971; TaYLor et al., 1963, 1965). The omegatrons were tuned to $\mathrm{N}_{2}$ and measured the height profiles of $\mathrm{N}_{2}$ over the altitude range between 140 and $290 \mathrm{~km}$. The neutral gas temperatures were derived from the scale height of the $\mathrm{N}_{2}$ profiles. The ion spectrometer (Pharo and Scotr, 1971) measures the ion concentrations in the mass range from 12 to $36 \mathrm{amu}$, sweeping at a rate of about 5 times per see.

The cylindrical probe experiment employed two redundant rhodium plated collectors and sweep voltage rates of 22 and $80 \mathrm{~V} / \mathrm{sec}$. A sweep repetition rate of $8 /$ seo was employed. The electron temperatures, $T_{\theta}$, were derived from both probes in the usual manner of fitting an exponential to the retarding region (BRACE et al., 1970). The ion concentrations, $N_{i}$, were derived from the ion currents collected when the probe was perpendicular to the velocity vector, following the method described by Taylor et al. (1963). Details of the data processing for these flights will not be discussed in this paper.

\section{The Measurements}

The pre-totality launch times of 1800 UT (1300 EST) for NASA 18.104 and 1827 UT (1327 EST) for NASA 18.105 were selected to permit resolvable changes to occur in the various measured parameters without encountering the non-linear rates of change that might be expected near totality (STuBBE, 1970). This was expected to simplify the theoretical analysis of the measured profiles. The area of unobscured solar disc, as viewed from the rocket trajectories, changed by a factor greater than four between the two flights thus assuring significant changes in solar energy input. As noted earlier, the obscuration at apogee of the two flights was 42 and 84 per cent, respectively. Figure 1 shows the path of totality as it passed Wallops Island at 1838 UT and the locations of apogee and the $100 \mathrm{~km}$ ascent and descent crossings of the two flights. The first rocket reached apogee at 1804 UT and the second at 1831 UT. Figure 2 shows the per cent obscuration along each leg of the trajectory. The descent data were selected for detailed analysis because of the generally smaller angles of attack for the $\mathrm{N}_{2}$ and ion measurements and the larger per cent obscuration. Figure 3 shows the $n\left(\mathrm{~N}_{2}\right)$ profiles measured at these times and the corresponding $T_{\mathrm{N}_{2}}$ 
Electron heating rate and ion chemistry in the thermosphere above Wallops Island

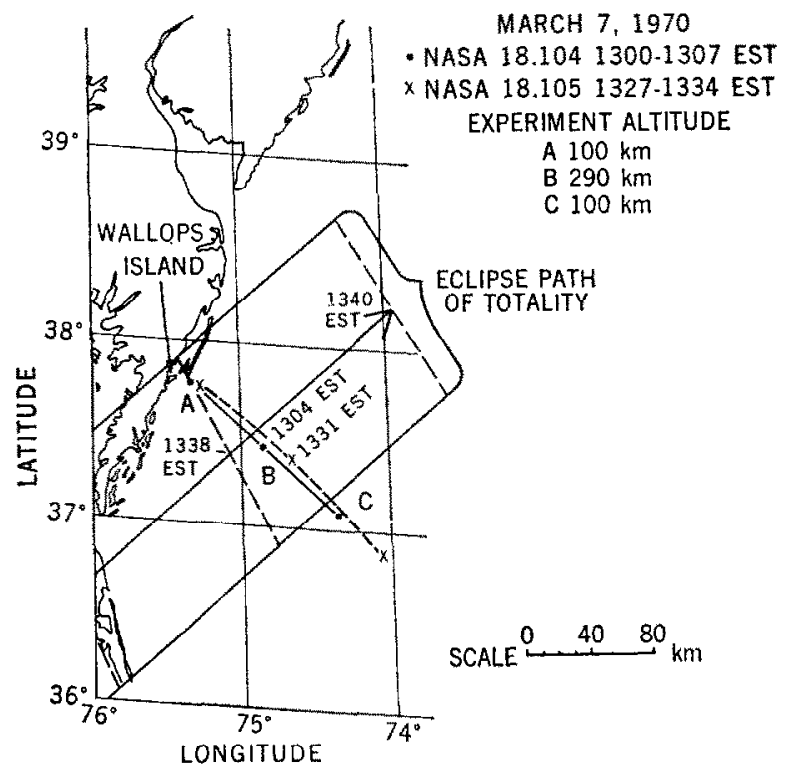

Fig. 1. The trajectories of NASA 18.104 and 18.105 relative to the path of the eclipse. The instruments travelled along approximately the same trajectories, reaching apogee about 34 min and $7 \mathrm{~min}$ before toiality.

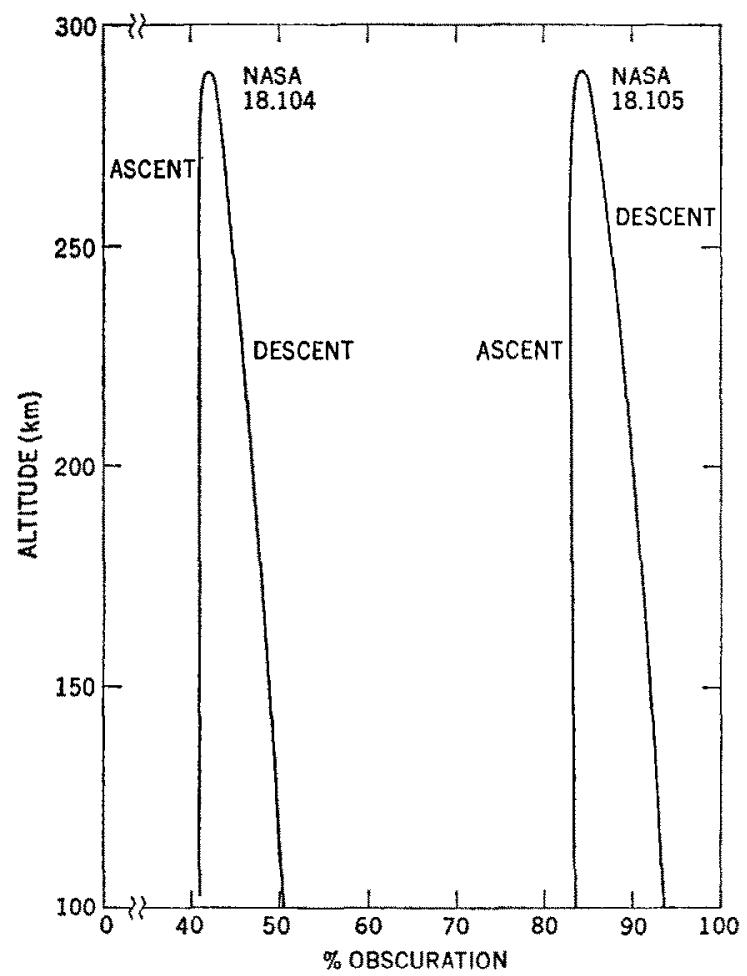

Fig. 2. The percentage obscuration encountered along the trajectories of the flights. Data from the descent leg of both flights have been employed in this paper. 


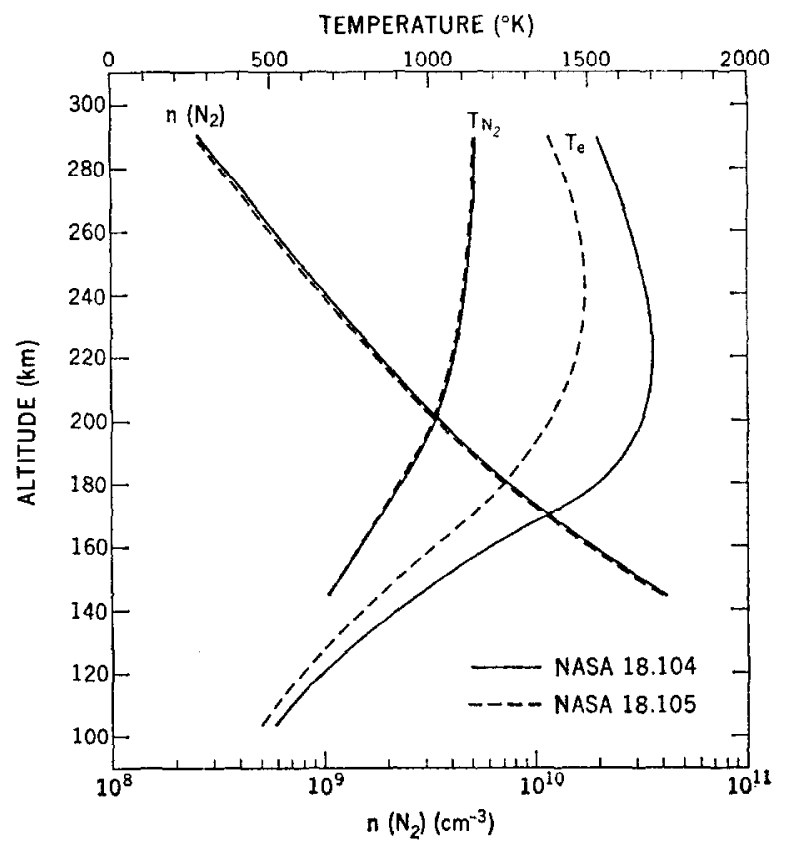

Fig. 3. The $n\left(\mathrm{~N}_{2}\right), T_{\mathrm{N}_{2}}$ and $T_{e}$ measurements taken on descent of the two flights.

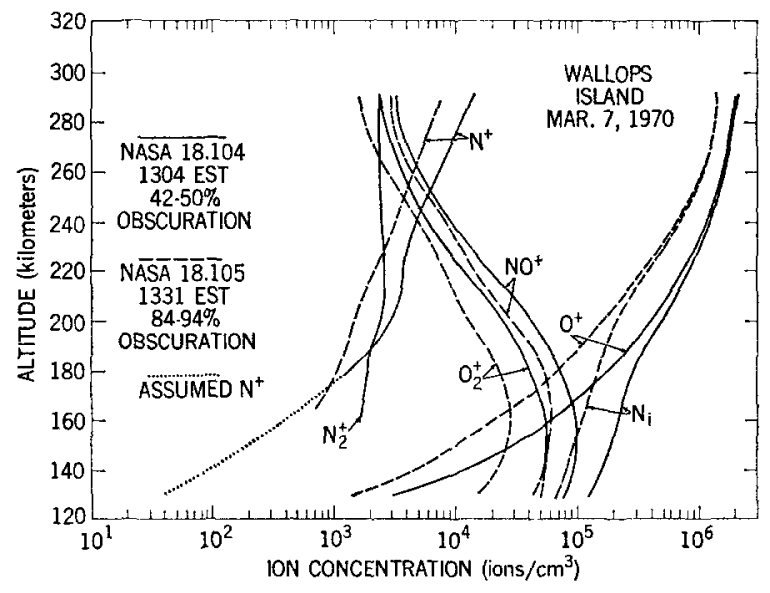

Fig. 4. The ion composition profiles.

profiles derived from the $\mathrm{N}_{2}$ scale heights. The $T_{e}$ profiles are also shown. There was essentially no resolvable change in either $n\left(\mathrm{~N}_{2}\right)$ or $T_{\mathrm{N}_{2}}$ within the 5 per cent relative accuracy of these measurements. $T_{e}$ decreased at all altitudes with the greatest decrease, 20 per cent, occurring at $200 \mathrm{~km}$.

The ion concentration profiles from the two flights, shown in Fig. 4, were derived by normalizing the constituent ion currents to the total ion concentration $N_{i}$ derived from the probe experiment. The latter agreed well with the $N_{e}$ profiles derived 
from simultaneous ionosonde records taken at Wallops Station $\left(J_{A C K S O N}\right.$ and McQUILLAN, 1970) except in the $F 1$-region where the $N_{i}$ values were 10-15 per cent lower. The 5-10 per cent agreement in the $E$ - and $F 2$-regions is considered acceptable considering the horizontal distance between Wallops and the descent legs of the trajectories. Tables 1 and 2 are tabulations of the measurements taken on descent of the two flights.

\section{Accuracy of the Measurements}

The factors that affect the absolute and relative accuracy of these measurements have been treated elsewhere, but it is appropriate to reiterate those factors that are especially important for the eclipse study. Since the goal of this investigation was to resolve the changes in each parameter during the eclipse we have attempted to maintain high relative accuracy by making the two sets of instruments as identical as possible. For this reason the omegatrons were calibrated simultaneously for $\mathrm{N}_{2}$ on the ground pressure calibration system normally used for this purpose. Their relative accuracy should be better than 5 per cent, including the possible errors in knowledge of the angle of attack as measured by Earth and Sun sensors on both flights. The $T_{\mathrm{N}_{2}}$ accuracy is also believed to be better than 5 per cent.

The accuracy of the probe measurements of $T_{e}$ were estimated to be 5 per cent on the basis of the quality of the exponential fits to the retarding regions and the good agreement between the measurements from the two identical probes on each flight. The $N_{i}$ values were estimated to be accurate within 10 per cent based on their agreement with the ionosonde $N_{e}$ profiles in the ascent $E$-region and $F$-region essentially above Wallops Island.

The concentrations of the constituent ions are expected to be accurate within 20 per cent. Before they were normalized to the $N_{i}$ profiles the individual ion currents were corrected for mass discrimination within the spectrometer using the same factors as used in previous applications (PHAro et al., 1971).

\section{The neutral atmosphere model adopted}

Since the physical interpretation of these data relies in part on a knowledge of the neutral composition of the thermosphere at the times of these flights, we have adopted the Jacchia Model that most closely matches the $n\left(\mathrm{~N}_{2}\right)$ and $T_{\mathrm{N}_{2}}$ profiles. Figure 5 and Table 3 represent the model used in the subsequent analyses of these data. To aid in matching the model, we extended the $\mathrm{N}_{2}$ and $T_{\mathrm{N}_{2}}$ profiles downward by interpolation with the essentially simultaneous Pitot-probe measurements of Horvath and Theon (1972) who measured the total atmospheric density and temperature up to $120 \mathrm{~km}$.

\section{Magnetic disturbance}

It should be noted that the eclipse occurred during a period of large magnetic disturbance. Table 4 lists the 3 -hr magnetic index, $a_{p}$, for a 3 -day period centered on the eclipse day. The value of $a_{p}$ was 67 at the time of these flights (see box in Table 4). This could be an important factor in the interpretation of the eclipse data, as there is increasing evidence that storms affect the temperature and composition of the neutral atmosphere (JACCHIA et al., 1967) at ionosphere heights thus 
L. H. Brace et al.

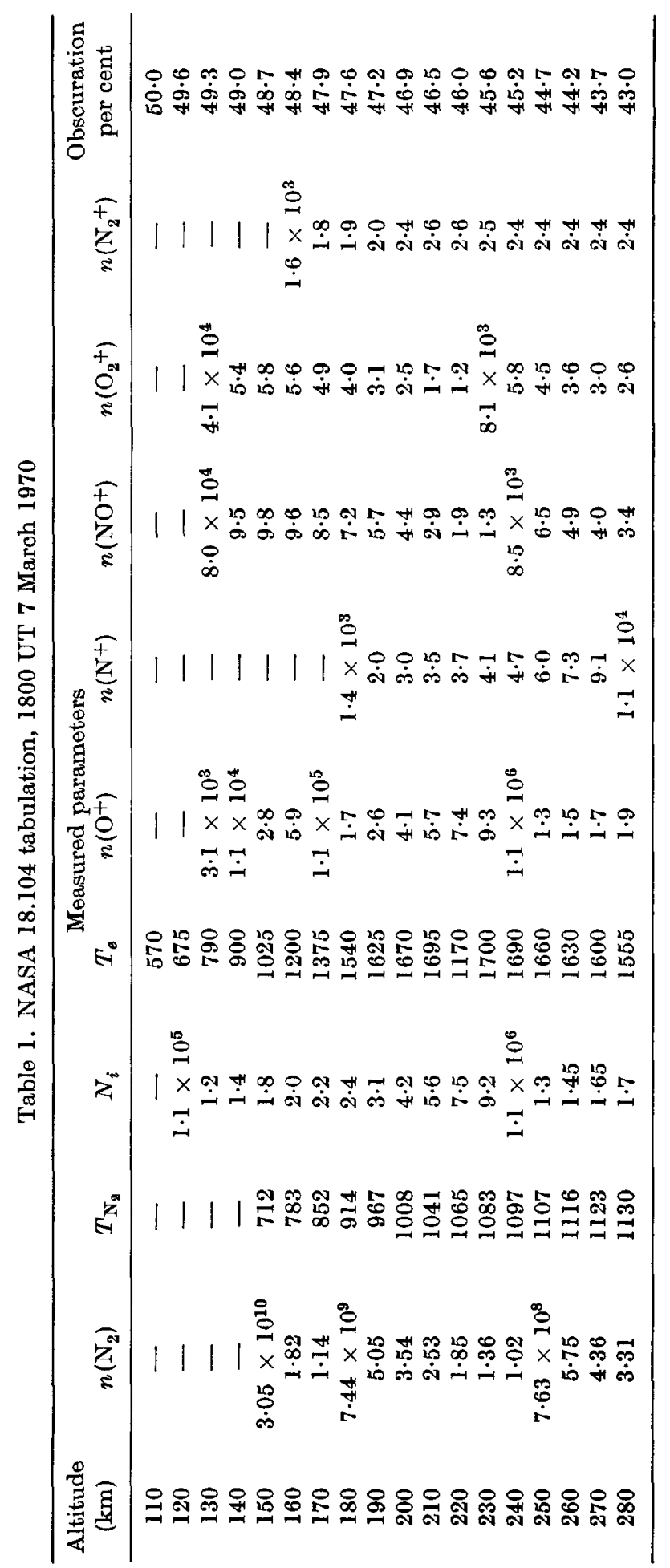




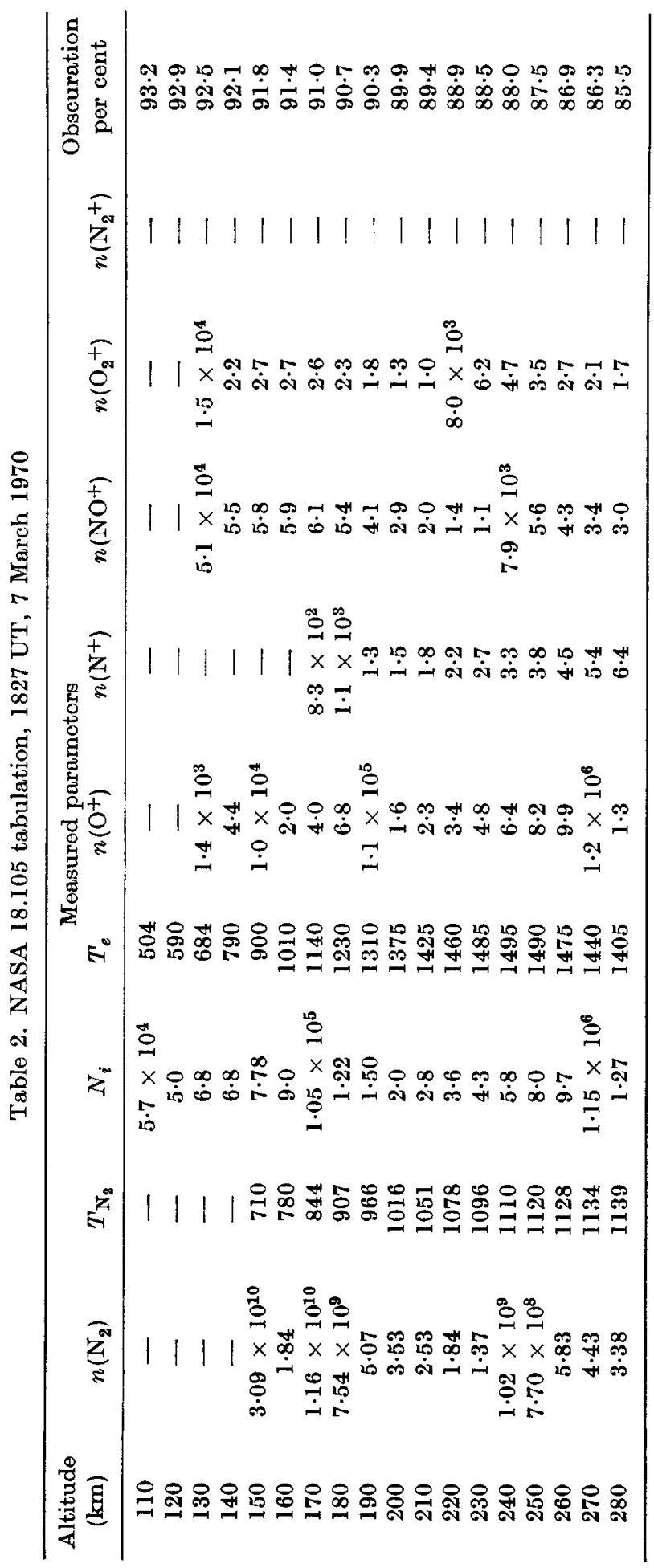




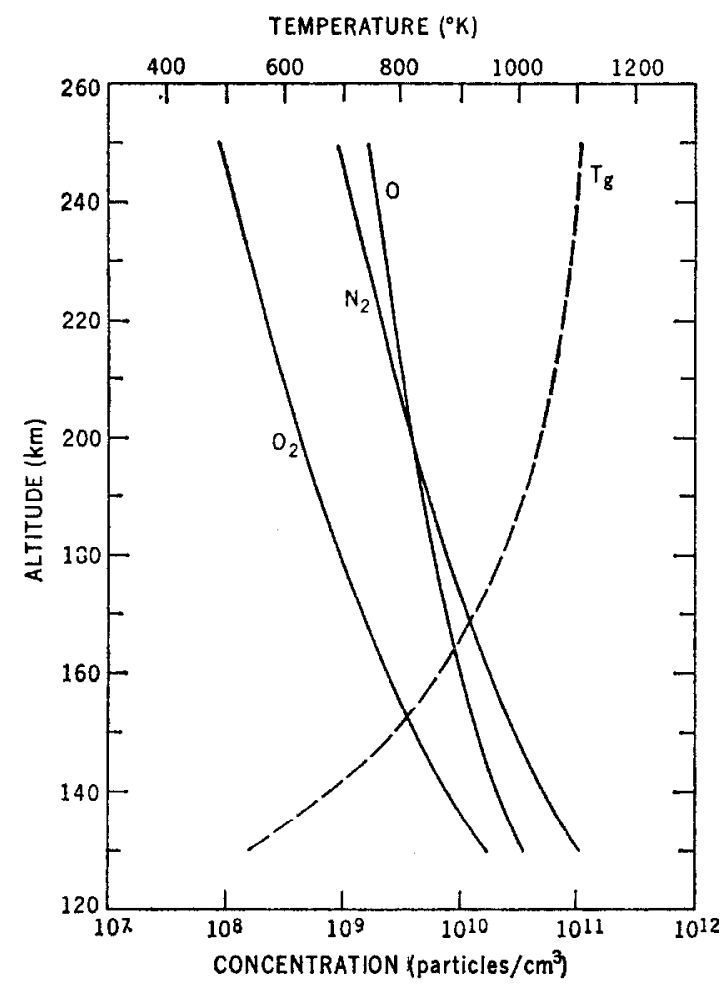

Fig. 5. The Jacchia Model Atmosphere best matching the $n\left(\mathrm{~N}_{2}\right)$ and $T_{\mathrm{N}_{2}}$ profiles measured on these flights.

Table 3. Jacchia model, $T_{\infty}=1120^{\circ} \mathrm{K}$

\begin{tabular}{|c|c|c|c|c|}
\hline $\begin{array}{l}\text { Altitude } \\
(\mathrm{km})\end{array}$ & $n(\mathrm{O})$ & $n\left(\mathrm{~N}_{2}\right)$ & $n\left(\mathrm{O}_{2}\right)$ & $T_{g}$ \\
\hline 130 & $3.5 \times 10^{10}$ & $1.0 \times 10^{11}$ & $1.8 \times 10^{10}$ & 550 \\
\hline 140 & $2 \cdot 1$ & $5.0 \times 10^{10}$ & $7.6 \times 10^{9}$ & 675 \\
\hline 150 & $1 \cdot 4$ & $2 \cdot 8$ & $4 \cdot 1$ & 785 \\
\hline 160 & 1.03 & 1.7 & $2 \cdot 4$ & 865 \\
\hline 170 & $8.0 \times 10^{9}$ & $1 \cdot 1$ & 1.5 & 925 \\
\hline 180 & $6 \cdot 2$ & $7.8 \times 10^{9}$ & $1 \cdot 0$ & 975 \\
\hline 190 & 4.9 & $5 \cdot 5$ & $6.7 \times 10^{8}$ & 1015 \\
\hline 200 & $4 \cdot 0$ & $3 \cdot 9$ & $4 \cdot 6$ & 1040 \\
\hline 210 & $3 \cdot 4$ & $2 \cdot 9$ & $3 \cdot 4$ & 1060 \\
\hline 220 & $3 \cdot 7$ & $2 \cdot 1$ & $2 \cdot 6$ & 1075 \\
\hline 230 & $2 \cdot 6$ & 1.5 & $1 \cdot 6$ & 1090 \\
\hline 240 & 1.9 & $1 \cdot 2$ & $1 \cdot 2$ & 1100 \\
\hline 250 & $1 \cdot 6$ & $9.0 \times 10^{8}$ & $8.4 \times 10^{7}$ & 1110 \\
\hline
\end{tabular}

Table 4. $a_{p}, 3-\mathrm{hr}$ magnetic index

\begin{tabular}{crrrrrrrr}
\hline Date $\backslash$ UT & $0-3$ & $3-6$ & $6-9$ & $9-12$ & $12-15$ & $15-18$ & $18-21$ & $21-24$ \\
\hline March & & & & & & & & \\
6 & 27 & 15 & 15 & 22 & 7 & 18 & 27 & 67 \\
7 & 56 & 32 & 15 & 27 & 32 & 39 & 67 & 67 \\
8 & 32 & 48 & 67 & 48 & 154 & 207 & 400 & 236 \\
\hline
\end{tabular}


altering the ion chemistry and thermal balance. We have not attempted to consider the storm effects explicitly, however.

\section{DISCUSSION}

The response of the thermosphere to a solar eclipse is of considerable interest as the solar obscuration introduces abrupt and, to some extent, calculable changes in the energy input to this region. Observations of the thermospheric response to the eclipse in turn provide the opportunity to test our theoretical understanding of the processes controlling its energy and chemical balance. These have been examined in the past using data obtained under normal daytime conditions (BRACE et al., 1969; PHARo et al., 1971). In this paper we employ the same type of analysis to eclipse time measurements. In particular we have examined primarily the changes in concentration and temperature observed between flights to evaluate the changing energy input and photochemical balance during the onset of the eclipse.

\section{The energy balance}

The magnitude of the electron temperature in the lower ionosphere is primarily determined by the local equilibrium between the electron heating and cooling rates (HANSON, 1962; Dalqarno et al., 1963). The electrons are created as photoelectrons that, in their thermalization process, heat the ambient electron population. The latter are cooled by elastic and inelastic collisions with ions and neutrals. Although the heating rate is difficult to calculate lacking simultaneous solar EUV information, its equivalent, the cooling rate, can be calculated readily from the measurements of these flights. In this section, we consider the electron heat balance in an attempt to evaluate the effects of the changing solar obscuration during this eclipse.

Following Brace et al., (1969), the $T_{e}, T_{\mathrm{N}_{2}}, N_{i}$, and $n\left(\mathrm{~N}_{2}\right)$ profiles, and the selected Jacchia model atmosphere (Fig. 5), were employed to calculate the electron cooling rates during these flights. We included the effects of heat conduction (BANKS, 1966) and the ion heating induced by thermospheric winds (STUBBE and CHANDRA, 1970), with a range of wind velocities assumed independent of height. The temporal variation of the internal energy was neglected, as a simple calculation shows that it contributed less than 1 per cent to the energy budget for the small changes that occurred during the eclipse.

Figure 6 shows the resulting cooling rates $Q_{e}(104)$ and $Q_{e}(105)$ from the two flights, where the family of curves represents the range of wind velocities assumed. The effects of winds become increasingly important above $220 \mathrm{~km}$ where the winds may cause $T_{i}$ to exceed $T_{g}$. The effects of heat conduction represent an additional uncertainty in the cooling rates at high altitudes. The heat conduction flux depends strongly upon the height gradient of $T_{e}$, a factor that cannot be derived accurately at the higher altitudes where the horizontal motion of the rocket and temporal changes may be comparable to the altitudinal variation of $T_{e}$. However, below $220 \mathrm{~km}$, the wind and heat conduction effects become negligible compared to local cooling, and the validity of the cooling rate profiles depends only upon the accuracy of the measurements and the model.

Figure 6 also compares the ratio of the cooling rates from the two flights (solid) with the ratio of the unobscured solar disc areas (dashed). If the heat sources arose 


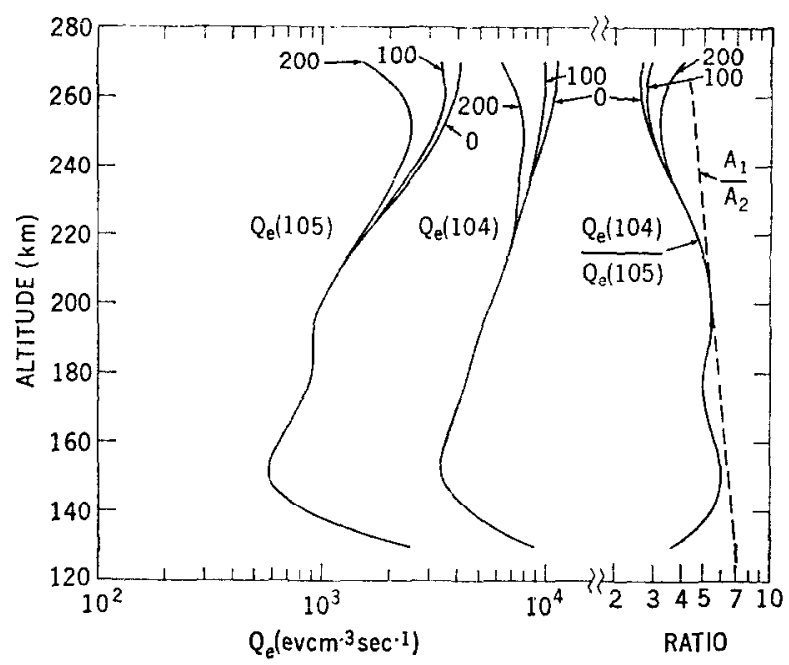

Fig. 6. The cooling rates calculated from NASA 18.104 and 18.105 profiles and their ratio $Q_{e}(104) / Q_{B}(105)$. Wind heating of the ions is included for speeds of 0 , $100,200 \mathrm{~m} / \mathrm{sec}$. The ratio of unobscured solar areas $A_{1} / A_{2}$ is shown for comparison.

entirely from radiation from the visible disc, these ratios would be comparable, and this appears to be approximately true in the range from 150 to $220 \mathrm{~km}$. However, at lower altitudes, the cooling rates did not decrease proportionally to the decrease in the visible solar disc, suggesting that some of the energy for this region originates outside the visible disc. This is not surprising because solar $\mathrm{X}$-rays originating in the corona are a known source of $E$-region ionization and heating. Similar evidence for a 'residual flux' was reported by SMrтH et al. (1965) who found little change in $T_{e}$ at lower altitudes during the South American eclipse of 1963.

\section{The ion chemistry}

In our analysis of the ion chemistry, we adopted the ultraviolet spectrum of HINTEREGGER et al. (1965) and scaled it upward linearly in accordance with the higher level of solar activity at the time of the eclipse $\left(F_{10 \cdot 7}=171\right)$. We then included the solar obscuration effect at each point along the trajectory and exposed the model atmosphere to these EUV fluxes and, following Pharo et al. (1971), calculated the height profiles of each ion constituent. This approach was modified to consider possible transient effects by including in the continuity equations the changes observed between flights in the various ion constituents. This correction was particularly important for the second flight where it accounted for about 30 per cent of the $\mathrm{O}^{+}$concentration above $200 \mathrm{~km}$. For all other ions, the effect was less than 4 per cent. From this it is perhaps valid to generalize that a steady state solution of the continuity equation is appropriate even during an eclipse for all ions except $\mathrm{O}^{+}$.

The neutral atmosphere model used for the ion chemistry analysis was identical to that used in the cooling rate calculations, and the $T_{e}$ measurements were employed to calculate the temperature dependent recombination rates. 
These initial calculated ion profiles (not shown) were found to agree with the measured ion profiles within a factor of 2 . This might be considered reasonable agreement in view of the uncertainty in the magnitude of the EUV flux, the hardening of the EUV spectrum implied by the cooling rate profiles, and the uncertainty in the absorption and ionization rates. The most pronounced deficiency in the initial theoretical result was the low $\mathrm{O}^{+}$concentration below $200 \mathrm{~km}$, a deficiency that in turn affected the other ion concentrations.

To attain a better fit to the measurements, two modifications were made. First, the absorption and ionization rates were increased by a factor of 2 from the values

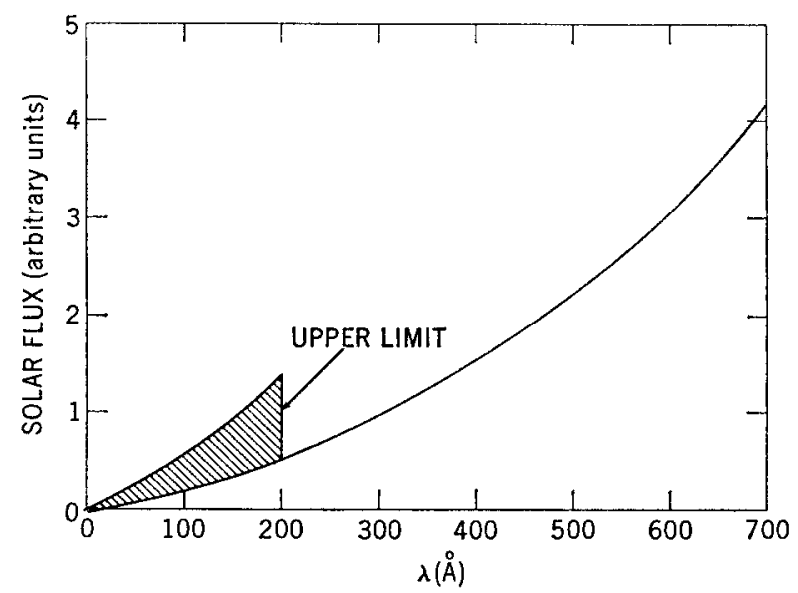

Fig. 7. Schematic model used for additional hard radiation (hatched) needed to account for the excess electron heating rates and deficiency of $\mathrm{O}^{+}$on the second flight. A factor of 3 enhancement was assumed at wavelengths below $200 \AA$.

Detailed spectrum is not shown.

given by Hinteregger et al. (1965) and used by Pharo et al. (1971) on non-eclipse measurements. These changes are within their quoted uncertainties. Secondly, we decreased the rate coefficient for the reactions

from

$$
\mathrm{O}^{+}+\mathrm{N}_{2} \rightarrow \mathrm{NO}^{+}+\mathrm{N}
$$

and

$$
6.5 \times 10^{-13} \quad \text { to } 3 \times 10^{-13} \mathrm{~cm}^{3} \mathrm{sec}^{-1}
$$

from

$$
\mathrm{O}^{+}+\mathrm{O}_{2} \rightarrow \mathrm{O}_{2}^{+}+\mathrm{O}
$$

$$
5.9 \times 10^{-12} \text { to } 3.5 \times 10^{-12} \mathrm{~cm}^{3} \mathrm{sec}^{-1} \text {. }
$$

Both of these rates are lower than laboratory derived rates (DuNkIN et al., 1968) by about a factor of 2 .

To introduce the amount of hard radiation that was inferred from the smaller than expected change in cooling rates, the EUV spectrum was scaled upward by a factor of 3 below $200 \AA$, as shown schematically in Fig. 7. Since the visible solar disc was only 7 per cent in the $E$-region of the second flight, this factor of 3 scaling 
suggests that 14 per cent of the radiation at these wavelengths originated outside the obscured area. From this one would predict that the X-rays are only about 86 per cent obscured by the Moon during totality.

The effect upon the $\mathrm{O}^{+}$population of intensifying the hard radiation by this scheme is shown in Fig. 8. The relative enhancement of $n\left(\mathrm{O}^{+}\right)$is shown for three altitudes assuming the upper wavelengths of $100,200,300,400$ and $500 \AA$, respectively. The wavelengths above $300 \AA$ are relatively less effective at low altitudes. Most of the desired enhancement results from wavelengths between 100 and $200 \AA$.

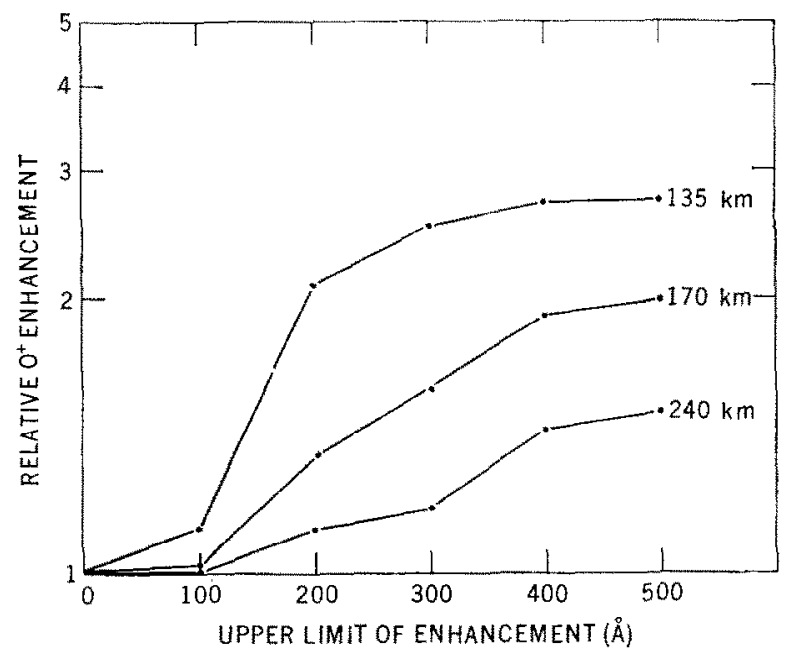

Fig. 8. The relative enhancement of $\mathrm{O}^{+}$at 135,170 and $240 \mathrm{~km}$ caused by the $X$-ray enhancements of the type shown in Fig. 7 assuming upper limits of 100, 200, 300,400 and $500 \AA$. The major $\mathrm{O}^{+}$enhancement at low altitudes occurs for wavelengths between 100 and $200 \AA$.

The final theoretical ion profiles are shown (dashed) in Figs. 9 and 10, and are compared with the measured ion profiles (solid). The agreement is generally better than 15 per cent and thus appears to fall within the combined experimental uncertainties.

\section{Uniqueness of the analysis}

It should be recognized that the analysis that leads to the theoretical ion profiles of Fig. 9 and 10 is not entirely unique with respect to the absolute values of ion concentration. Perhaps the greatest uncertainty lies in our ignorance of the solar EUV spectrum at the time of the eclipse. Had we used a spectrum different from that presented by HINT'REGGER et al. (1965), somewhat different adjustments of the ionization, absorption and reaction rates would have been necessary to fit the observations.

However our conclusion that a hardening of the spectrum occurred during the eelipse is on firmer ground as it is based solely on the relative changes in the ion concentrations and electron temperatures between the two flights. The changes in 

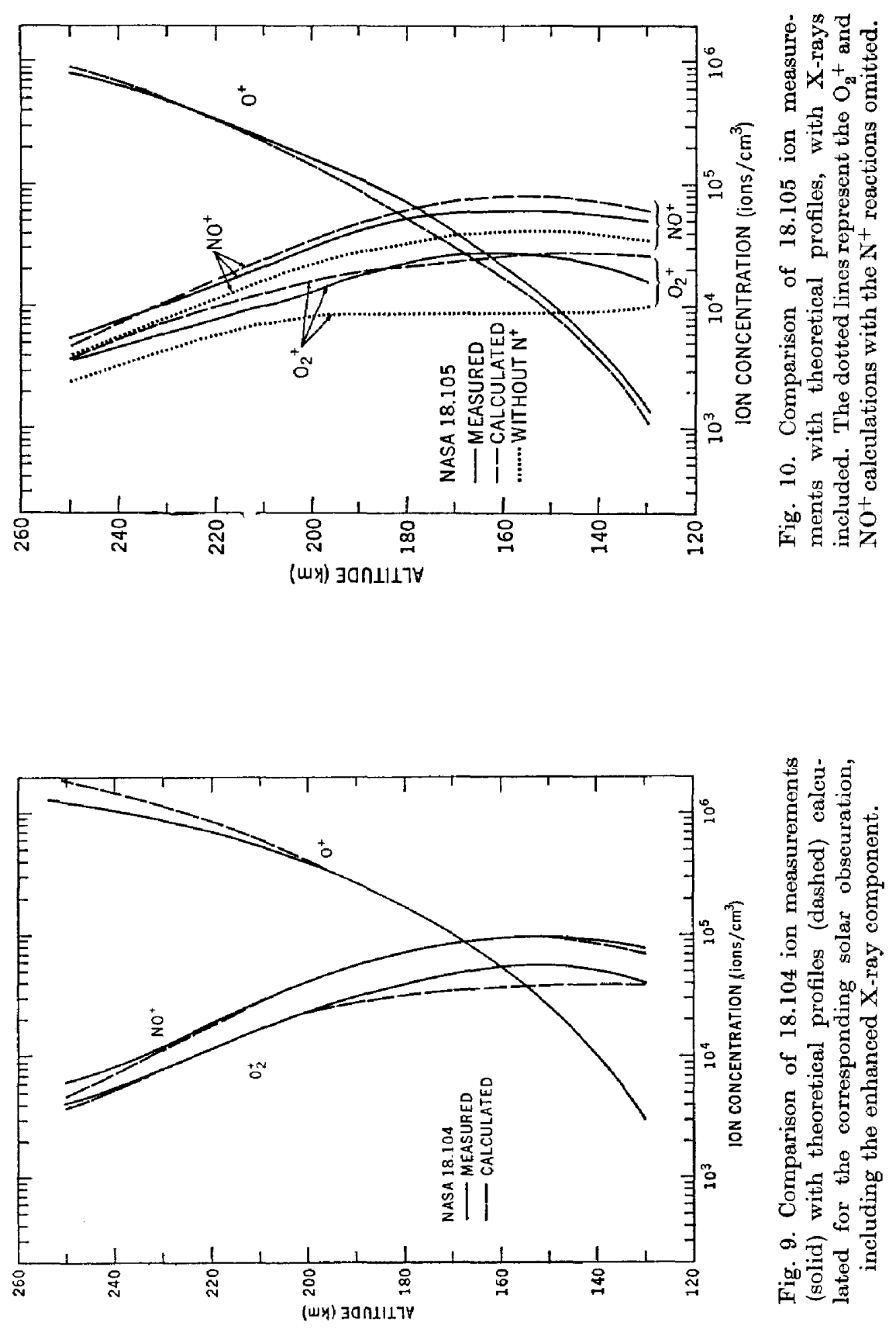
these parameters require enhancements in the 100-200 $\AA$ range. The form we chose to introduce this enhancement (Fig. 7), is not unique, however.

\section{The effects of the minor ion reactions}

The calculations of STUBBE (1970) for this eclipse disagree significantly with regard to the behavior of ion composition during the eclipse. Although some of the discrepancy could be accounted for by suitably modifying the solar EUV input, one reason for the failure in Stubbe's model to predict the $\mathrm{NO}^{+}$and $\mathrm{O}_{2}{ }^{+}$correctly is because it does not consider the role of the minor constituents $\mathrm{N}^{+}$and $\mathrm{N}_{2}+$ in the following reactions:

$$
\begin{aligned}
\mathrm{N}^{+}+\mathrm{O}_{2} & \rightarrow \mathrm{NO}^{+}+\mathrm{O} \\
\mathrm{N}^{+}+\mathrm{O}_{2} & \rightarrow \mathrm{O}_{2}^{+}+\mathrm{N} \\
\mathrm{N}_{2}^{+}+\mathrm{O}_{2} & \rightarrow \mathrm{O}_{2}^{+}+\mathrm{N}_{2} \\
\mathrm{~N}_{2}^{+}+\mathrm{O} & \rightarrow \mathrm{NO}^{+}+\mathrm{N} .
\end{aligned}
$$

Both of the $\mathrm{N}^{+}$reactions are important as the $\mathrm{N}^{+}$concentrations are significant in the lower ionosphere and their rates are of the order of $5 \times 10^{-10} \mathrm{~cm}^{3} \mathrm{sec}^{-1}$ (Fensenfeld et al., 1965; Ferquson, 1967). To illustrate the importance of $\mathrm{N}^{+}$, we have included in Fig. 10 the solutions in which these reactions have been neglected (dotted). Without $\mathrm{N}^{+}$, the $\mathrm{O}_{2}^{+}$concentrations are a factor of 3 too low at $160 \mathrm{~km}$ and $\mathrm{NO}^{+}$is low by almost a factor of 2 . The $\mathrm{N}_{2}{ }^{+}$reactions have less influence on the $\mathrm{O}_{2}{ }^{+}$and $\mathrm{NO}^{+}$concentrations but are not negligible. They account for about 20 per cent of the $\mathrm{O}_{2}^{+}$and $\mathrm{NO}^{+}$. PHaro et al. (1971) have included these reactions in their analysis of the normal daytime thermosphere above Wallops Island and obtained similarly good fits to the composition measurements.

\section{The neutral atmosphere}

It is perhaps appropriate to comment upon the apparent lack of response of the neutral atmosphere to the eclipse. As noted earlier, no resolvable changes in $n\left(\mathrm{~N}_{2}\right)$ or $T_{\mathrm{N}_{2}}$ occurred between these flights. However, owing to the magnetic disturbances occurring at the time of the eclipse $\left(a_{p}=67\right)$ and throughout at least the previous $24 \mathrm{hr}$, one should perhaps not assume that the response to the eclipse was entirely normal. Any energy transport from higher latitudes would tend to mask the eclipse effect and further contribute to a smaller response of the atmosphere.

For two other reasons it remains understandable that the eclipse caused little change in the neutral atmosphere. The first is related to the long response time of the neutral atmosphere and the second is related to the highly localized nature of the eclipse.

The total internal energy in a $1 \mathrm{~cm}^{2}$ column above $120 \mathrm{~km}$ is about

$$
Q \approx 5 \times 10^{4} \mathrm{ergs} \mathrm{cm}^{-2} .
$$

This energy can be conducted downward at the $120 \mathrm{~km}$ level with a flux of $2.7 \times 10^{-1}$ ergs $\mathrm{cm}^{-2} \mathrm{sec}^{-1}$ with a resulting characteristic time of about $1.85 \times 10^{5} \mathrm{sec}$ or about $51 \mathrm{hr}$, a time much greater than the $27 \mathrm{~min}$ between the flights. Furthermore, vertical and horizontal heat convection (VollaNd and MaYr, 1970) can supply 
energy to and from the adjacent atmosphere at rates of $5 \times 10^{-1} \mathrm{erg} \mathrm{cm}^{-2} \mathrm{sec}^{-1}$ and $4 \times 10^{-1} \mathrm{erg} \mathrm{cm}^{-2} \mathrm{sec}^{-1}$, respectively, leading to characteristic times of the order of $1 \times 10^{5} \mathrm{sec}$. These also are much longer than the eclipse time, thus it is not surprising to find little change during the eclipse. Since the solar obscuration affects only a very small region at any given instant, horizontal transport tends to fill up this 'energy hole' from the adjacent and fully illuminated regions without significantly affecting the global energy budget. The effect of this process is to further damp the eclipse response of the thermosphere. This aspect has been considered by VOLLAND and MAYR (1971) who show that small scale energy disturbances are ineffective in exciting density variations. The excitation efficiency varies as $1 / n^{2}$, where $n$ is the wavenumber corresponding approximately to the ratio of the global dimension to the size of the disturbance.

STUBBE (1970) predicted that the exospheric temperature would decrease during the eclipse, at the end of the eclipse falling about $120^{\circ}$ lower than its normal day value. However, Stubbe's model overestimates the variations to be expected during the eclipse. It is one-dimensional and therefore does not consider the damping effects of horizontal mass and energy transport, factors that are expected to be significant.

\section{Conchusions}

Measurements of ions, electrons and neutral particles at two times during the eclipse have permitted the electron heat balance, the ion chemistry and the neutral atmospheric response to be evaluated. Both the electron heat balance and ion chemistry suggest a hardening of the solar spectrum as the eclipse progresses, with X-rays attenuated about a factor of 3 less than the EUV flux. The EUV flux appears to have been attenuated in proportion to the visual obscuration. The role of the minor ions $\mathrm{N}^{+}$and $\mathrm{N}_{2}+$ is found to be important in the production of $\mathrm{NO}^{+}$and $\mathrm{O}_{2}{ }^{+}$. These minor ions are usually neglected, but are especially important during an eclipse when photoionization sources for $\mathrm{NO}^{+}$and $\mathrm{O}_{2}{ }^{+}$are less significant. The lack of variation of neutral temperature and concentration appears consistent with the long thermal and transport time constants of the thermosphere.

\section{BANKS P. M.}

Brace L. H., Findlay J. A. and Carignan G. R.

Brace L. H., MaYk H. G. and Carignan G. R.

Dalgario A., MoElroy M. B. and MOFFETT R. J.

Dunkin D. B., Fehsenfeid F. C., SCHMELTEKopf A. L. and Ferguson F. F.

Fersenfeld F. C., Sommeltekopf A. L. and Ferguson E. E.

Ferguson E. E.

Hanson W. B.

\section{References}

1966 Planet. Space Sci. 14, 1105.

1970 Space Research XI. North-Holland, Amsterdam.

$1969 J$. geophys. Res. 74, 257.

1963 Planet. Space Sci. 11, 463.

1968 J.chem. Phys. 49, 1365.

1965 Planet. Space Sci. 13, 919.

1967 Rev. Geophys. 5, 305.

1962 Space Research III, p. 282, North-Holland, Amsterdam. 
Hinteregger H. E., Hall L. A. and SCHMIDTKE G.

Horvath J. J. and Theon J. S.

JACCHIA L. G., SLOWEY J. and VERNIANI $\mathrm{F}$.

JACkson J. E. and MCQuillan C. J.

Pharo M. W., III, Scott L. R., Mayr H. G., Brace L. H. and Taylor H. A.

Pharo M. W., III and Scott L. R.

Smith L. G., Accardo C. A., Weeks L. H. and McKinnon P. J.

Spencer N. W., Brace L. H., Carignan G. R., Taeusch D. R. and NiEManN $H$.

Spencer N. W., Newton G. P., Carignan G. R. and Taeusch D. R. StubBe P.

Stubbe P. and Chandra S.

Taylor H. A., Brace L. H., Brinton H. C. and Sмith C. R.

Taylor H. A., Brinton H. C. and SMith C. R.

VOLLAND H. and MAYK H. G.

Volland H. and MaYr H. G.
1965 Space Research $V$, p. 1175. NorthHolland, Amsterdam.

1972 J. Atmosph. Terr. Phys. 34, 593.

$1967 J$.geophys. Res. 72, 1423.

1970 GSFC document X-625-70-394 (Oct. 1970).

1971 Planet.Space Sci. 19, 15.

1971 Goddard Space Flight Center document X-621-71-105 (Mar. 1971), presented also at Spring AGU, Washington, D.C. (1971).

1965 J. Atmosph. Terr. Phys. 27, 803.

$1965 J$ Jeophys. Res. 70, 2665.

1969 Space Research $X$, p. 389. North-Holland, Amsterdam.

$1970 \quad J$. Atmosph. Terr. Phys. 32, 1109.

$1970 J$ J. Atmosph. Terr. Phys. 32, 1909.

1963 J.geophys. Res. 68, 5339.

$1965 J$. geophys. Res. 70, 5769.

1970 Annls Géophys. 26, 907.

$1971 \quad J$.geophys. Res. 76, 3764. 